\title{
Can a National Requirement Affect the Gender-Balance Approach?
}

\author{
Maria Teresa Nardo $^{1} \&$ Romilda Mazzotta ${ }^{2}$ \\ ${ }^{1}$ Business Administration, Department of Political and Social Sciences, University of Calabria, Italy \\ ${ }^{2}$ Business Administration, Department of Business Administration and Law, University of Calabria, Italy \\ Correspondence: Maria Teresa Nardo, University of Calabria, Department of Political and Social Sciences, Cubo \\ IB, Via P. Bucci, Arcavacata di Rende, Cosenza, 87036, Italy. E-mail: maria.nardo@unical.it
}

Received: January 20, 2018

Accepted: February 26, 2018

Online Published: March 18, 2018

doi:10.5539/ijbm.v13n4p11

URL: https://doi.org/10.5539/ijbm.v13n4p11

\begin{abstract}
In 2009, Italian law required, at public administration, to provides a report on performance and gender. We ask how regulatory provision has affected Italian regions, because these last have a special responsibility in the adoption of standards related to gender. The aim of the paper is to fill up the information gap existing and to investigate practices adopted as a result of national legislation. The results show that the implementation of gender budget is timidly brought by Italian region. Therefore, we conclude that the presence of a standard does not necessarily create the conditions for public administration to adopt a gender approach, and more attention to the gender issue is required.
\end{abstract}

Keywords: Italian regions, performance, gender

Article Classification - Research paper

\section{Introduction}

Attention to gender issues rises since the early 1990s and especially when, after the Fourth World Conference on Women, at the Beijing Platform for Action of 1995, start the interest on the gender mainstreaming as the appropriate mechanism for achieving the goals of gender equality (CIDA, 1999; Moser, 2005; Moser \& Moser, 2005; Mahapatro, 2015). The Gender mainstreaming focuses their attention on systems, process and norms that generate inequalities and is view a systematic approach for integrating gender perspective in all political, economic and societal spheres so that women and men benefit equally and inequality is not perpetuated (Bendl \& Schmidt, 2013; Page, 2011). Today, the gender impact approach is relevant in key international organizations and in the national contexts of many western democracies (Eveline, Bacchi \& Binns, 2009; Bendl \& Schmidt, 2013). The goal of changing budget and policies is to promote gender equality that is achievable only if "raise awareness of the gender issues and impacts of budget an policies" and "promote accountability of governments for their gender equality commitments" (Sharp, 2002, p. 88). Gender balance, therefore, is intended to draw the public body to consider gender equity not only as a goal to achieve, and to be reported and communicate, but also as a criterion for guiding their budgetary policies (Sharp, 2002; Pulejo, 2011). In this sense the gender balance, as consequence of application of gender mainstreaming, is to put in place a process of cyclical analysis and evaluation of the effects and the impacts that these policies produce at the gender level (Galizzi, 2011). Therefore, we can identified two level of carrying out gender balance: ex-ante (first level) and ex-post (second level). At the first level, ex-ante approach, gender perspective means refer to need and then at the gender effects of all government programs and policies during the budgetary process (Stotsky, 2007; Chakraborty, 2014), we refer to this last as gender budget. This mean that the formulation of the budget incorporates an analysis of public expenditure and methods of raising public revenue, from a gender perspective, identifying the implications and effects for women and girls as compared to men and boys (Sharp, 1999). Budgets are a powerful tool for achieving development objectives, and act as an indicator of commitment to the set government policies. Budgets reflect how governments mobilize and allocate public resources, and how they aim to meet the social and economic needs of their people. The gender budget is not a production of a separate "women's budget" (Sharp, 2002; Budlender, Elson, Hewitt \& Mukhopadhyay, 2002) but rather a tool that allows at the public budgetary policy plays a major role in achieving the objective of gender equality. This is very important if we consider that budgetary policies are likely to affect men and women differently, since they play different roles in society and demonstrate different consumer behavior. 
Incorporating gender perspective in the ex-post phase (gender audit) mean analyzed the existing budget through a gender lens (Chakraborty, 2014) to check on the effectiveness, efficiency and transparency of public spending and allows administrators public and civil society to become more aware of the effect of public policies on women and men. The ex-post approach has been focused on the differential effect of the budget on women and men and on different groups of women and men (Budlender, Sharp, \& Allen, 1998; Galizzi, 2011) but only ex-post, which is a practice known as the gender audit (Addabbo 2011; Bettio, Rosselli, \& Vingelli, 2003; Galizzi, 2011). This document named gender audit (or gender budget analysis or gender report) could be a separate document or joint in other audit document. The need of gender audit arises from the fact that the achievement of gender equality requires not only a government spending target at equal opportunities between sexes, but also a systematic gender-sensitive policy including an analysis of the effect of public policies and budgets on men and women (Elson, 1993; Budlender et al., 1998; Addabbo, Lanzi, \& Picchio, 2010).

Several are the research on gender perspective, mainly containing a descriptive account of the experiences of the gender budgeting (Elson, 2003; Sarraf, 2003) in different countries (Chakraborty, 2006, 2007; Rao \& Chakraborty, 2006; Chakraborty \& Bagchi, 2007) or that analyze the effect of policies and budget on gender (Elson, 1993; Addabbo et al., 2010). Several are the paper the focuses attention on gender audit (Addabbo, 2011; Bettio et al., 2003). With reference to Italy, the scientific contributions are limited and recent. Existing study present an overview and understanding of the experiences developed in Italy in via spontaneous but little explored is the practice at the highest levels of government (State and Region) (Pulejo, 2011; Galizzi, 2012; Martini, 2011). Current studies show that the practice of gender budgeting has spread in the local authorities, but at the same time recognize, in reality, there is a need for the prospect of a policy integration and cooperation among different levels of local government. The observation of the phenomenon with reference to Italy is particularly significant because from 2010 the legislature introduces the gender budgeting at all levels of government, though it refers to it as a gender budget analysis. This paper aims, therefore, to reduce the gap in the current literature that often does not consider the need to study the detailed rules of defining and adopting policies in relation to the law. In order to answer to our research question, statutes and laws were analyzed to detect the presence of specific provisions on gender and to verify how many Italian regions have developed gender budgeting and what purpose has been attributed to it.

The rest of the paper is organized as follows. The following section present a literature review on gender balance (gender audit and gender budget). Our methodology is introduced in the next section and describes how the information are collected and analyzed. We then present our analysis and discussion and then the conclusions.

\section{Literature Review}

The dissemination of gender approach can relate to the gender mainstreaming process, understood as a strategy for promoting equality and equal opportunities between men and women integrating gender perspective in all political, economic and societal spheres so that women and men benefit equally and inequality is not perpetuated (Bendl \& Schmidt, 2013, p. 2011).

The literature on gender has developed since 1970s receiving coverage in feminist theories as well as philosophical and historical writings (Lehman, 2012; Galizzi \& Siboni, 2016).

Attention of researcher to this issue growing since the 90s as of result of the Beijing Platform for Action of 1995 that introduced the gender mainstreaming as the appropriate mechanism for achieving the goals of gender equality (CIDA, 1999; Moser, 2005; Moser \& Moser, 2005; Mahapatro, 2015). After this, the gender budget is identified as initiative that contribute to gender mainstreaming (Elson, 2003).

The first experiments carried out focused on the process, seeking to analyze and evaluate how the choices of local or national governments were addressed to all citizens. It found expression in the items of expenditure and revenue of a public budget and produced, in reality, very different effects for men and for women, since they vary in their role in family, society, and the economy (Elson, 1999).

Consequently, there are numerous publications on gender approach, mainly containing a descriptive account of the experiences. These studies cover topics that range from conceptualizing gender budgets (Elson, 2003; Sarraf, 2003) to developing tools and methodologies for evaluating budgets through gender lenses, (Balmori, 2003; Budlender \& Hewitt, 2003; Budlender et al., 2002; Elson, 2003, Sharp, 2002; Sarraf, 2003). Several studies evaluate gender budgeting in different countries, these include Chakraborty (2007) that focus on India; Chakraborty (2006) centered on Mexico; Rao \& Chakraborty (2006) on Morocco; Chakraborty \& Bagchi (2007), with reference to South Africa, suggest that, despite efforts to formulate gender-responsive budgets, many countries still have gender-blind budgets. The reasons for this include ignorance, gender-biased culture, lack of gender budgeting expertise and limited gender-disaggregated data (Sarraf, 2003). Several are also the study on 
gender audit (Addabbo, 2011; Bettio et al., 2003).

To the best of our knowledge, there are few studies research on gender perspective with reference to Italy. Existing studies generally present an overview and understanding of the experiences (Galizzi, 2012; Martini, 2011). Galizzi (2012) analyzes the gender balance of different kind of public bodies (regions, provinces, Mountain townships and municipalities) in order to map the present experiences and identify the prevalent theoretical model used in order to have a gender perspective. Pulejo define a mapping of experiences of gender perspective within the territorial government information systems and accounting. Pulejo instead conceives gender budgeting as a tool for communication and social reporting while Pulejo (2011) analyzes the autonomy of gender budgeting than the tools of social accountability (Farneti, Pozzoli \& Nardo, 2005). Martini (2011) analyze the behavior of local authorities on the subject of gender budget analysis.

In this paper, we analyze therefore the Italian context with reference to the field less analyzed of Region. The observation of the phenomenon with reference to Italy is particularly significant because from 2010 the legislature introduces the gender budgeting at all levels of government. Our aim is to investigate, whether and how Italian Regions are taking a role in promoting gender equality in terms of adoption of gender balance after that legislation introduced gender perspective, the trends of phenomena and the critical issue still present in practical application. The study compared to others already is more focuses on accountant aspects rather than those sociological but not investigate the impact of the adoption of gender approach.

\section{Methodology}

This research starts from the consideration that the studies on gender perspective in the public sector are limited, despite the legislature and the European and national institutions considering it a necessary tool for the application of the principles of equal opportunity. Even the few existing researches are focused on local and provincial levels, while this paper concentrates on already well researched contexts: the regions.

In Italy the competences and responsibilities are shared on the basis of the Constitution and the legislative system among the different levels of the institutions (state, region, province, municipality).

We chose to investigate the regions from among all public organizations based on the following considerations:

- regions are entities operating on large territories therefore significant in terms of the individuals involved and of effects that the choice can produce in a gender perspective;

- the regions, according to the Italian Constitution, have the power to legislate, therefore, the principles laid down by the central government. The region that decides to include the presence of women in their governing bodies or that decides to adopt gender budgeting generally intervenes with actions amending its constitution and not because it has provided a legislation imposed from above by the central government.

Qualitative research appears more consistent because the objective of observation is an innovative phenomenon and this justifies the use of an exploratory investigation process (Creswell, 2009). Qualitative analysis on the documents has as limitations the lack of a standardized form that characterizes all social accountability processes at an early stage of their implementation makes it difficult to compare the space-time of the documents (Bailey, 2006). In this work with the budget end of generally indicate documents offering a reading of the public budget from a gender perspective.

In order to respond to our research questions we considered the 20 Italian regions. We verified how many Italian regions have developed gender perspective and what purpose has been attributed to it, checking alignments or inconsistencies in the doctrine (Ricci, Siboni \& Nardo, 2014; Galizzi, 2012; Leardini \& Rossi, 2011, Pulejo, 2011). Then we detect the presence or absence of information related to the topic of gender as required by the regulations starting form this document we are also able to identify the state of the art, the methods and the function attributed to the documents on gender, as well as any limits and trends. Subsequently we then defined if the standard has impacted on the reality. Data were collected by verifying the presence of gender documents on the websites of each Italian region. The research was completed in February 2015.

The framework of analysis used was, with the necessary adaptations made, similar to a survey proposed by Ricci (2014) on sustainability reporting in the regions. Each experience of the region, through the analysis of the budget document of its kind, was observed in terms of:

- Origin, when the first document of gender was set up and what has been the driving force?

- Source, is there a legal obligation on the development of specific regional gender perspective?

- Definition, what definition and functions are attributed to gender perspective? 
- Methodology, how is the document produced? What approach and methodology does it use?

- Presence of other sustainable report: Does the region prepare other tools of sustainability beyond that of gender?

To complete the analysis we examined the individual experiences of gender budgeting in order to extrapolate the trends of the phenomenon and the critical issues still present in its practical application. Then we compare the case studies.

\section{Implementing Gender Perspective in Italian Regions}

In Italy, gender equality and equal opportunities are aspects required by the Constitution (Article 51 paragraph 1 of the Constitution) and have a legal framework on gender equality provided by the national Code of Equal Opportunities between women and man established in 2006 (Legislative decree 198/2006). The code introduced the principle of gender mainstreaming in the drafting of laws, regulations and administrative acts, and in all policies and activities. Subsequently to the Directive of 23 May 2007, "Measures to implement equality and equal opportunities between men and women in public administration", issued by the Minister for reforms and innovations in public administration and the Minister for Rights and Equal Opportunities. This directive recommended to the government to use the gender budget with the hope that these statements become established practice in the activities of social reporting administrations. Later, in 2009, the Decree 150/2009, implementing Law 15/2009, art. 10 paragraph 1 letter b, provides for gender balance among the documents that the government must produce together with the Report on performance by 30 June each year. Each region, with its regional law, must make its approach to the gender. References to gender are, therefore, usually detectable in the statutes and in the regional law.

Several are the regional that had approved statutes dealing with gender issues. In $75 \%$ of cases the reference to gender issues can be found in the first part of the Statute (in the introductory phase the basic lines that inspired the action of the regional government are already highlighted) other calls are made in the section on general principles of organization and operation and finally in the section on institutional guarantees, by the creation of variously named bodies (Tab. 1). Some Statutes (Note 1) refer to positive action with regard to the electoral laws.

Table 1. Gender issues in the Italian regional' statutes

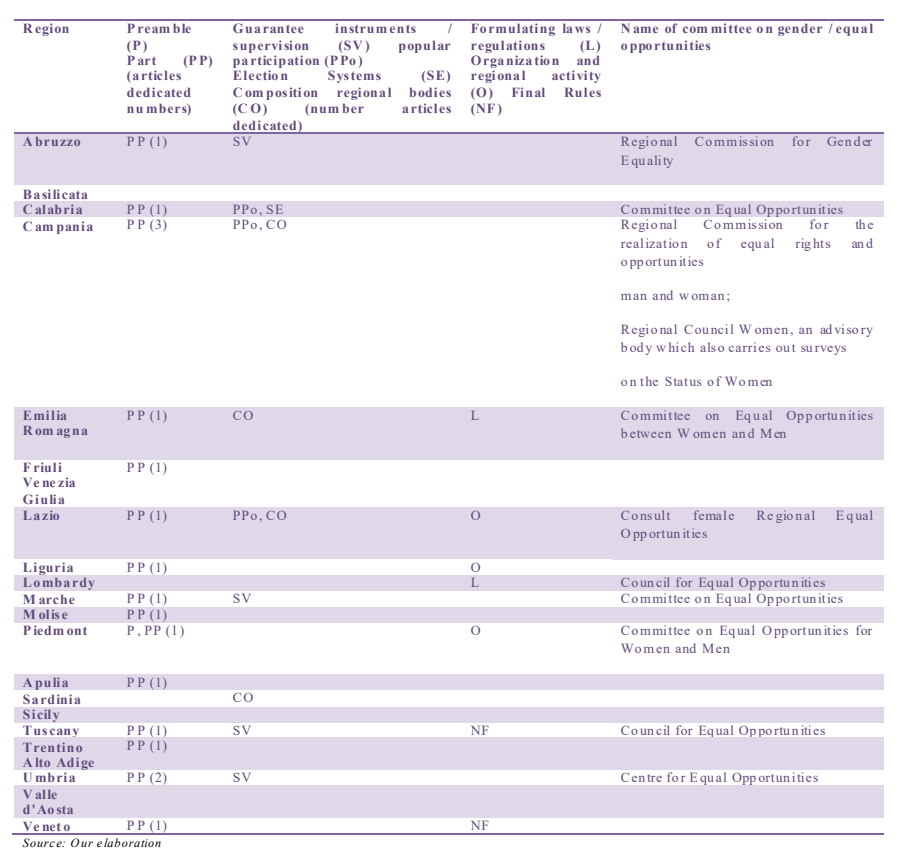

The Lombardy region provide, in its statute, ad hoc norms that explicitly protect the principle of equal opportunities. In this statute the first article of Title I, of the general principles, is dedicated exclusively to the issue of equality between men and women and equal opportunities (art. 11). This article uses the term "equal democracy" with regard to the social, cultural, economic and political context, in other words recognizing the 
opportunity for women to be able to compete with men in each activity and each public body. The Campania Statute, in art. 5, discusses gender differences. It is not "protection" or "exploitation" of gender difference and specifies that the promotion of equality must be done with planning, implementation, monitoring and evaluation by the region itself.

In the regions, there are few laws that introduce gender budgeting. The regions that have enacted laws to regulate the general protection of gender identity are Liguria (August 1, 2008 Law no. 26 on the integration of equal opportunity policies and then by law November 10, 2009 no. 52 with rules against discrimination related to sexual orientation or gender identity), the Marche (February 11, 2010 no. 8), Piedmont (March 18, 2009 no. 8), Tuscany (April 2, 2009 no. 16). The Liguria region is definitely a good example in that, a short time ago, it issued even two laws, one directed to the identification of a series of promotional activities, which introduce gender policies, a regional gender mainstreaming monitoring system and "Osservatorio Regionale".

The regions that have introduced a gender budget are the Liguria region with Articles 8 and 9 of Law no. 26 of 2008 , which provides for the formulation of a budget as a reporting tool for integrating gender policies. The regional legislation of Piedmont is perhaps more organic. The commitment of the Piedmont Region in favor of women is evident from the constitution, ratified in the mid-seventies, for the first time in Italy, of the Regional Women, as a permanent body of consultation with the Regional Council on issues of interest to women. Established in 1976, it gathers feminine forces organized in parties or associations that have the inclusion of women in society as their primary purpose. It is the constitution of 1986 in Piedmont, at the Regional Council, the Regional Commission for the implementation of Equal Opportunity (RL no. 46/1986 "Establishment of the Regional Commission for the realization of equal opportunities between men and women). While the Establishment of the Council for Elected Piedmont dates back to the Regional Law no. 44/1996. The consultation body, the first in Italy to be constituted, gathers all the designated Directors of Piedmont in elected Assemblies of First Instance and the Presidents of the institutions of equal opportunities within the region, in order to promote and increase the presence of women in politics and institutions.

The Piedmont Region, in law no. 8 of 2009, first established the general objectives for gender policies and, among these, the preparation of a gender budget, i.e. the evaluation of the effect of fiscal policies on gender in the planning stage, as well as on the application the budget. Then attached to the Board a person was placed in charge of setting the guidelines and methods useful for the preparation of such financial statements, for regional, local authorities and others. Similar criteria are followed in the Tuscan regional law that introduces the concept of "gender citizenship" (Law No. 16 of 2009), which in addition to setting goals, mainstreaming of a general and a gender budget on "the lines" of other regional laws, identifies the type of actions that the region should encourage, among which, also, the establishment of a "database of knowledge of women" in which are inserted the curricula of women with proven scientific, cultural, artistic, professional, economic, or political experience, working or living in Tuscany. In the Apulia Region in 2008, the RL 8 March 2007 was enforced. This regional law on gender-related policies instituted the 'Ufficio Garante di Genere', an office with tasks of monitoring and assessing the implementation of Law No. 7/2007 from the establishment of a database with the curriculum of women willing to take on managerial positions, to the elaboration of a gender-budget for the Apulia Region and an annual report about the condition of women in the area. In Liguria in 2008, the regional government implemented a regional action establishing the regional law of 1 August 2008 No. 26 integrating gender-related policies for equal opportunity in the region. In 2012, the Abruzzo Region subscribed an Agreement on Equal Opportunity with provinces and municipalities for the promotion of the topic of work-life balance.

\section{Gender Perspective in Practice in Italian Regions by the Gender Balance}

There are four regions that have implemented gender budgeting: Liguria, Tuscany, Marche and Piedmont. There are only three that make it available on the company website. The gender document is not posted on the Liguria region website therefore we analyze the gender balance of Piedmont, Tuscany and Marche regions. There are 7 gender balance (document of three regions for different years).

The following summarizes the most significant elements emerged from the analysis of gender documents of Marche, Piedmont and Tuscany and the data emerging from performance documents.

\subsection{The Gender Perspective in the Marche Region}

The Marche Region has long been engaged in the activity of Gender Budgeting. This activity was undertaken for the first time in the year 2005. For Region Marche, the gender budget allowed a deepening of the effect of individual policy interventions. "A gender budget must help develop the policy makers and the technical structure of the entities the ability to take account of gender differences where these affect the behavior of the different reactions of men and women to the same policies (e.g. access to services, mobility, education, 
participation, use of public spaces, ...)" (Preface, Gender Budgeting, 2004).

Already in the first edition, in the year 2005, with reference to some items of expenditure of the Financial Statement of the year 2004, the budget analysis was conducted by adopting the VISPO methodology. This method consists of two activities:

1. Reclassification of balance sheet, according to the gender impact on the beneficiaries of the expenditure and income in specific policy areas;

2. Analysis of the financial progress.

Also in the 2007 version the VISPO methodology is adopted.

Table 2. Gender issues in the Marche region

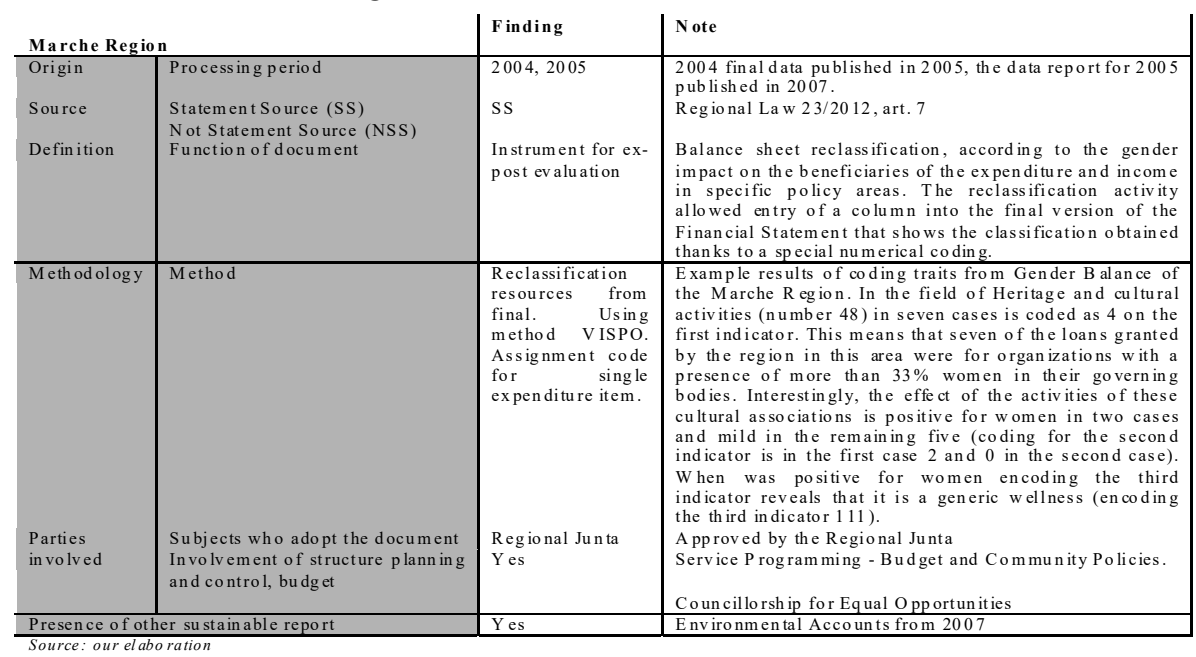

The latter aspect is relevant in the case of interventions not explicitly aimed at training or at the labor market; for example, with reference to the 'culture' sector, financing activities was taken into account and the operators present in the above areas considered from the gender dimension, not only including direct beneficiaries (cultural organizations) but also indirect, i.e. end-users, in this case the spectators. Three indicators were chosen to assess these aspects. With reference to point A) "Indicator 1." The effect of the extent of spending on the production and employment structure while with reference to point B) "Indicator 2." The presence or absence of an effect of the extent of spending on the final recipients, whether direct or indirect; "Indicator 3." whether the type of effect of the measurement of spending on final recipients is direct or indirect.

\subsection{The Gender Perspective in Tuscany Region}

The Tuscany Region before reaching elaboration of the Gender Budget predisposed annually reports on "positive action for regional employees" within the meaning of Article 38 of Regional Law (RL) 1/2009, by the Directorate General Organization. The first edition of the gender was approved by the Government on December 2013. The second edition was prepared with the same methodology. The source of the gender budget is in the Regional Law 16/2009, art. 13.

For the Tuscany Region the Gender Budget is an analysis tool that aims to give administrators and citizens the chance to reflect on the different effects of policies on women and men, giving them the chance to improve the use of public resources with greater equity and efficiency on behalf of all citizens and all the towns.

The regional budget for 2010-2012 was observed with the objective of obtaining a reclassification of resources from a gender perspective. The budgetary resources were reclassified (grouped) in thematic areas or political intervention program Regional: competitiveness of the regional system and human capital; the rights of citizenship and social cohesion; sustainability, quality of land and infrastructure; governance, efficiency of the PA and international projection. Indirect, Direct and Neutral actions on the reclassification of gender were identified within the thematic areas. Direct actions concern all the initiatives and activities aimed at promoting equal opportunities and specific interventions aimed at women: events for the dissemination of the culture of equality, the promotion of female entrepreneurship, action against exploitation and prostitution, etc. 
Indirect actions are divided into:

- Support instruments, which shall include actions not specifically addressed to women, but able to influence their lives in an important way. It is, in general, the area involving education, training and work, services and the elderly, to vulnerable or at risk of marginalization and social exclusion;

- Services to persons, grouping services anyway related to the person and to the quality of life of the individual, but not directly related to the family and the need for conciliation. These are mainly activities involving social and health policies and local public transport;

- Sharing of context, those group activities to improve the context in which the individual lives. They are for example policies for industry, culture, green areas, urban security.

Table 3. Gender issues in the Tuscany region

\begin{tabular}{|c|c|c|c|}
\hline \multicolumn{2}{|l|}{ Tuscany Region } & Finding & Note \\
\hline Origin & Processing period & 2013,2014 & Final data on the previous year. \\
\hline Source & $\begin{array}{l}\text { Statement } \text { Source } \\
\text { (SS) } \\
\text { Not Statement } \\
\text { Source (NSS) }\end{array}$ & SS & Regional Law $16 / 2009$, art. 13 \\
\hline Definition & $\begin{array}{l}\text { Function } \\
\text { document }\end{array}$ & $\begin{array}{l}\text { Instrument for ex- } \\
\text { postevaluation }\end{array}$ & Monitoring and Evaluation Tool \\
\hline Methodology & Method & $\begin{array}{l}\text { Reclassification } \\
\text { resources from final. } \\
\text { Using activity } \\
\text { indicators. }\end{array}$ & $\begin{array}{l}\text { E.g. Indicators: } 458000 \text { EUR activated; } 31 \text { Shares held; } \\
9,000 \text { students and teachers involved. }\end{array}$ \\
\hline \multirow[t]{2}{*}{ Parties involved } & $\begin{array}{l}\text { Subjects who adopt } \\
\text { the document }\end{array}$ & $\begin{array}{l}\text { Regional Junta } \\
\text { which transmits it to } \\
\text { the } \\
\text { Council Regional }\end{array}$ & $\begin{array}{l}\text { Approved by the Regional Junta and transmitted to the Regional } \\
\text { Council with the Regional Plan for gender citizenship } \\
\text { programming tool in the field of equal opportunities. }\end{array}$ \\
\hline & $\begin{array}{l}\text { Involvement } \quad \text { of } \\
\text { structure planning } \\
\text { and control, budget }\end{array}$ & Yes & $\begin{array}{l}\text { Sectors responsible for gender policies, strategic control and } \\
\text { management of Statistics. } \\
\text { Councillorship for Equal Opportunities, Councillorship for } \\
\text { budget }\end{array}$ \\
\hline & & & Social Report since 200 \\
\hline
\end{tabular}

\subsection{The Gender Perspective in the Piedmont Region}

The Piedmont Region published its first gender budget in 2007. For the Piedmont Region, the Gender budget is an integrated tool whose aim is to improve the accountability and communicative approach of the region. In its first document of Gender Budget, the Piedmont Region claims to have married the approach of performance-oriented gender budgeting with that of human development, both then referred to the specificities of the program of the regional mandate. In the case of the Piedmont Region these were reinterpreted (ex-post) intervention policies from a gender perspective in the light of the different effect on women and men, referring to the principles underlying the program, in particular, taking out the concept of sustainability in social terms. Methodologically, the Piedmont Region as well as analyzing financial data, conducted a timely examination of the budget of the planning documents from a gender perspective.

Table 4. Gender issues in the Piedmont region

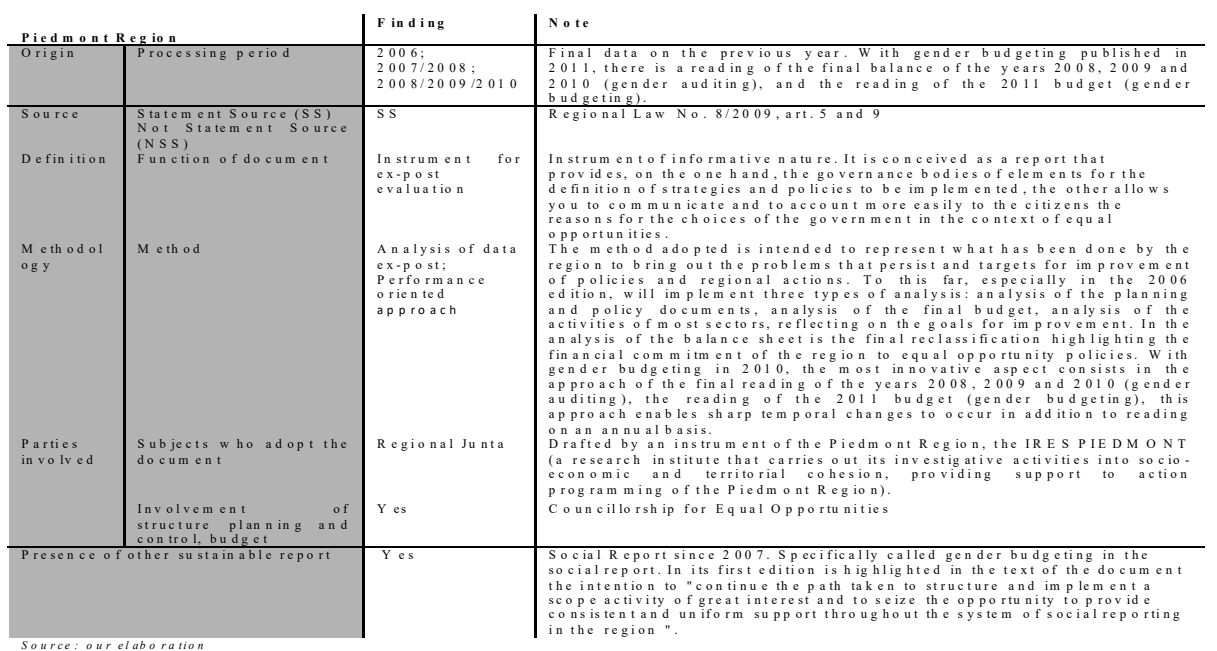




\subsection{Comparation on Gender Issue in Marche, Tuscany and Piedmont regions}

The table 5 below shows a comparison is between the evidence that emerged in the analysis of the three cases investigated in the six points of observation. In all three cases the element that promotes gender approach is the presence of a regional law. In all three cases the gender document is mainly seen as a document ex post (all regions examined) and in one case the ex-ante (Marche). The Piedmont region with the instrument intended to represent what has been done by the region to bring out the problems persist and targets for improvement of regional policies and actions. Instead the Marche region in developing own gender document estimates also the impact ex-ante. This is also the result of the method used since the model is linked to the lively is applied in European programs. The main difference that you will notice in the three cases is unrelated to their own method. The approaches are different, therefore the documents are not comparable in terms of substance, at the same time there is a predominant method. The regions seem to have chosen the method to be used depending on the role assigned to the same document. In all cases the document is approved by the council and only in the case of Tuscany is forwarded to the regional council in order to give it greater visibility.

Table 5. Comparation on gender issue in Marche, Tuscany and Piedmont regions

\begin{tabular}{|c|c|c|c|c|}
\hline \multicolumn{2}{|c|}{ Aspect of analysis } & \multirow{2}{*}{$\frac{\text { M arche Region }}{2004,2005}$} & \multirow{2}{*}{$\frac{\text { Tuscany }}{2013,2014}$} & \multirow{2}{*}{$\begin{array}{l}\text { Piedmon t } \\
2006,2007 / 2008 ; \\
2008 / 2009 / 2010\end{array}$} \\
\hline Origini & Processing period & & & \\
\hline Source & $\begin{array}{l}\text { Statement Source } \\
\text { (SS) } \\
\text { Not Statement Source } \\
\text { (NSS) }\end{array}$ & SS & SS & \\
\hline Definition & Function of document & $\begin{array}{l}\text { In strument for ex -ante and ex- } \\
\text { post evaluation }\end{array}$ & $\begin{array}{l}\text { Instrument for ex-post } \\
\text { evaluation }\end{array}$ & $\begin{array}{l}\text { Instrument for ex-post } \\
\text { evaluation }\end{array}$ \\
\hline Methodology & Method & $\begin{array}{l}\text { Reclassification resources } \\
\text { from final. Using method } \\
\text { VISPO. Assignment code for } \\
\text { single expenditure item. }\end{array}$ & $\begin{array}{l}\text { Reclassification } \\
\text { resources from final. } \\
\text { Using activity in dicators. }\end{array}$ & $\begin{array}{l}\text { Analysis of data ex-post; } \\
\text { Performance oriented } \\
\text { approach }\end{array}$ \\
\hline Parties in volved & $\begin{array}{l}\text { Subjects who adopt } \\
\text { the document }\end{array}$ & Regional Junta & $\begin{array}{l}\text { Regional Junta which } \\
\text { transmits it to the } \\
\text { Regional Council }\end{array}$ & Regional Junta \\
\hline & $\begin{array}{l}\text { Involvement of } \\
\text { structure planning and } \\
\text { control, budget }\end{array}$ & Yes & Yes & Yes \\
\hline Presence of other & $\begin{array}{l}\text { sustainable report } \\
\text { tion }\end{array}$ & Yes & Yes & Yes \\
\hline
\end{tabular}

\section{The Results of the Analysis of Regional Experiences}

The analysis of the Regional experiences highlight that the practice of processing the gender balance was not common in the Italian regions. Of a total of 20, only four bodies process the Gender budget: Liguria Region, Region of Tuscany, Marche Region and the Piedmont Region. Those that most distinguish themselves, at least in terms of continuity and timeliness are Tuscany and Piedmont. The Tuscany Region published gender budgeting in 2013 and in 2014, the Piedmont Region from 2006 to 2011. The research shows, however, how the gender tools are used after the recent introduction in the regions. Also the regions that have approached the Gender Balance demonstrate a simplistic application of the tool. Gender analysis adopted by the regions appears extremely low because such analyzes are conducted from the budget documents and therefore at the decision-making process concluded. The tool used in the situations analyzed, differs both from gender auditing and gender budgeting, it is rather an act of information that chronicles the activities that the region has undertaken in the development of gender culture over a given period. Gender budgeting means "paying attention to the analysis of the effect of public policies on women and men; inserting the gender perspective at all levels of the process of building public budgets; aiming at restructuring revenues and expenditures in order to promote equality between the sexes" (Ricci et al., 2014, p. 126). The regions would rather not use gender budgeting to restructure and redefine public spending in order to promote gender equality, much less integrate the gender perspective in the programs and in budgetary policies. No significant situations have managed both to integrate a gender perspective at all levels of the budgetary process and to restructure revenues and expenditures in order to promote equality between the sexes.

Gender budgeting implies that, within programs, actions and policies, revenue and expenses are assessed and restructured in order to ensure that the priorities and needs of women are taken into account in the same way as those men, with the ultimate goal of achieving equality between women and men. Under this approach, gender analysis and gender impact assessment requires due consideration in the various stages of planning, design, implementation, monitoring and evaluation of the budget. Experience shows that especially in the design phase and definition of the budget this does not occur. It is common, in fact, to find an activity of ex-post reclassification of the budget from a gender perspective than ex-ante design of the budget. Altogether, the results 
from the survey did not demonstrate a wide consensus regarding the definitions of the gender document.

There are many issues that emerge from the analysis of the gender documents:

- the gender budget (document) assumes mostly a disclosure purpose; it is used, in fact, to provide information on the activities carried out on gender;

- The preparation of the gender budget does not affect the planning of activities, much less the allocation of financial resources. Even when referring to programming, the activity consists of an analysis of long-term plans, aimed at highlighting what has been taken up of the principle of equal opportunities policies and major planning documents (program mandate DPFR, DPSO, Regional Spatial Plan);

- The development of gender budgeting requires the involvement of all the heads and sectorial officials taking part in the construction of the public budget, this being to ensure that the gender perspective is integrated in the definition of revenue and expenditure in all budget policies. This is not found in the regional contexts studied.

- The methodology does not address specific standards or guidelines;

- There is no form of audit;

- The involvement of stakeholders is not structured but occasional.

The analysis does not show any correlation between the dynamics of legislation on gender policies and the presence of gender budgeting. The different diffusion of the gender tool can be attributed to many differences, not only at the level of economic and social development, but also at the levels of transparency of public action, degree of empowerment of women, political representation and participation in civil society of the regions.

Rather, the positive correlation is evident for the regions that have long been using reporting tools such as the budget sustainable social and environmental balance. In fact, the Piedmont Region since 2007 to now has produced its Social Report and the Tuscany Region since 2009, while the Marche Region has had an established business with environmental balance since 2007 (Ricci et al., 2014). Only the Liguria Region had, for the period 2005/2010, a single experience of budget mandate which was not followed by further documents (see table 6). These administrations are particularly open to questions of gender and to social participation, and already possess some interpretative and cultural tools for making their importance visible, even in the absence of consolidated techniques of gender. This is certainly the case of the regions of Piedmont, Toscana and Marche which were already committed to budget transparency, accountability and to initiatives of social reporting. This leads us to believe that the adoption of the Gender Balance is mainly present in the regional situations where the tools of sustainability reporting are now consolidated. Even the Piedmont region in its first edition of the gender budget highlights the need to "seize the opportunity to make it consistent and uniform throughout the plant's social reporting of the Region" (Gender Budgeting Piedmont Region, 2006).

Table 6. Gender Budgeting, sustainability reports and regulatory dynamism

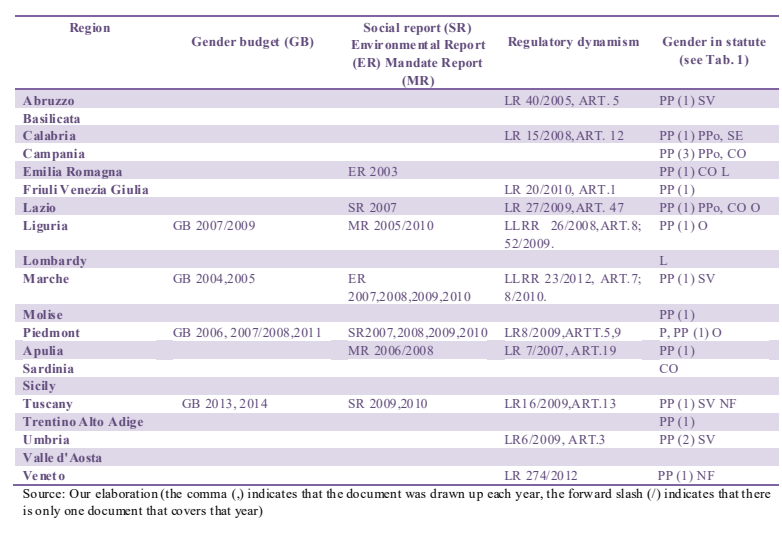

\section{Conclusion}

The aim of paper is contribute to fill up the information gap existing in relation to the regions and to the same behavior as a result of national legislation. Italy, with respect to the issue of gender, can be considered a state with an advanced legal system. Nevertheless, in the various classifications that affect gender equality, the nation is positioned at low levels. The legislation is, in fact, clear and at advanced levels as it requires the introduction 
of gender budgeting, but on a practical and application-level Italy is delayed. The results of our analysis reveal that the regions are timidly intervening on the regulatory framework. Turning to the implementation of gender mainstreaming most efforts are considered inconsistent and generally involve only a few activities rather than a coherent and integrated process. The few statutes that provide for gender aspects do not provide clear requirements, but merely state principles. The number of regions reporting on gender is somewhat limited. Available online, there are very few gender balance, often produced with reference to only one year and then abandoned, there are very few cases of regions that have prepared the gender budget for several years (such as the Piedmont Region). The data show that there is a tendency to adopt an approach closer to the definition of "accountability", understood as a "duty" to give an account of the specific actions which a person / entity was responsible, and then tied to the reporting tool (see Tuscany region). The methodologies of gender budgeting are complex and diverse, therefore, the regions tend to simplify using tools they already know.

Overall, the analysis shows that the regions are distant from gender budgeting also due to specific statutory provisions that tend to pull the actual gender relations tools, such as the relationship of performance and financial statements.

A demonstration of this is common to find in that the gender budget, if any, is processed by the financial sector in the region and there are only a few cases involving areas such as programming or strategic planning, and in no case the involvement of the entire organization.

In fact, the approach that is being developed is closer to the forms that sustainability reporting take rather than the process of gender budget analysis (Tuscany and Piedmont Regions). In Italy, therefore, Gender Budgeting is part of the broader issue of performance reporting and social control. It is not excluded that this approach, in the most careful form, can take the measure of the Performance gender budgeting analysis, which, through the analysis of the results obtained or anticipated by the administration, evaluates the capability to promote equity, efficiency, effectiveness in the planning and implementation of public policies. In 2011 the Piedmont region, adopting this methodological approach, issued guidelines in support of local authorities for the development of gender budgeting. The performance of gender budgeting, in line with recent Italian regulations regarding transparency and corruption, has intrinsic aims to promote transparency in the allocation and distribution of public resources, enhancing a gender perspective tendency of administrations to move towards an approach of accountability, which requires that all institutions belonging to the public life of a country "account for" their actions to the citizenship. Gender budgeting in this perspective therefore falls within the accountability tools that are the social and sustainability report.

The above results must be viewed in light of two major limitations of the study: survey documents and limited number of experiences.

This study enriched and somehow bridged the gap in the literature in particular as regards the scientific investigations in the area of gender perspective at the medium levels of Italian public institutions such as regions, nonce have shown how an intervention regulations can guide incorrectly approaches that were spontaneously giving better results.

\section{Acknowledgments}

Although the paper is the result of an equal joint effort by the two authors, their primary individual contributions are reflected in the following sections of the paper: Romilda Mazzotta sections 1, 2, 4, and Maria Nardo 3, 5, 6, 7.

\section{References}

Addabbo, T. (2011). Gender Budgeting in the Capability Approach from Theory to Evidence. Conference: Counting on Women-Gender, Care and Economics. Retrieved from http://www.gcu.ac.uk/media/gcalwebv2/theuniversity/centresprojects/wise/addabbo.pdf

Addabbo, T., Lanzi, D., \& Picchio, A. (2010). Gender budgets: a capability approach. Journal of Human Development and Capabilities, 11(4), 479-501. https://doi.org/10.1080/19452829.2010.520900

Balmori, H. H. (2003). How Gender Budget initiatives are implemented in practice. Paper presented at the Pan Island Gender Budget Conference, Pan Islands.

Bendl, R., \& Schmidt, A. (2013). Gender mainstreaming: an assessment of its conceptual value for gender equality. Gender, Work \& Organization, 20(4), 364-381, doi 10.1111/j.1468-0432.2011.00584.x.

Bettio, F., Rosselli, A., \& Vingelli, G. (2003). Gender Auditing dei bilanci pubblici. Retrieved from http://www.fondazionezaninoni.org/pdf/quaderno3.pdf 
Budlender, D., \& Hewitt, G. (2003). Engendering Budgets A Practitioners' Guide to Understanding and Implementing Gender-Responsive Budgets. UK, Commonwealth Secretariat.

Budlender, D., Elson, D., Hewitt, G., \& Mukhopadhyay, T. (2002). Gender Budgets Make More Cents Country Studies and Good Practice. UK, Commonwealth Secretariat.

Budlender, D., Sharp, S., \& Allen, K. (1998). How to do a gender sensitive budget analysis: contemporary research and practice. Commonwealth Secretariat and AusAid, London and Canberra.

Chakraborty L. (2014). Integrating Time in Public Policy: Empirical Description of Gender-specific Outcomes and Budgeting. Working paper, Levy Economics Institute.

Chakraborty, L. (2006). Fiscal Decentralisation and Gender Responsive Budgeting In Mexico Some Observations. Publications Unit, National Institute of Public Finance and Policy.

Chakraborty, L. (2007). Gender Responsive Budgeting and Fiscal Decentralization in India: A Preliminary Appraisal. Working Paper 46, New Delhi: National Institute of Public Finance and Policy.

Chakraborty, L. S., \& Bagchi, A. (2007). Fiscal Decentralisation and Gender Responsive Budgeting in South Africa: An Appraisal. Working paper. India: National Institute of Public Finance and Policy.

CIDA, Canadian International Development Agency (1999). CIDA's Policy of gender equality, Hull, Quebec: CIDA.

Council of Europe. (2005). Gender budgeting. Final report of the Group of specialists on gender budgeting (EGS-GB). Retrieved from http://www.coe.int/t/dghl/standardsetting/equality/03themes/gender-mainstreaming/EG-SGB\%282004\%29 RAPFIN_en.pdf

Creswell, J. W. (2009). Research design: Qualitative, quantitative, and mixed methods approaches. Los Angeles: SAGE.

Elson, D. (1993). Gender aware analysis and development economics. Journal of International Development, 5(2), 237-247. https://doi.org/10.1002/jid.3380050214

Elson, D. (1999). Commonwealth Gender Responsive Budget Initiative. Background Papers London: Commonwealth Secretariat.

Elson, D. (2003). Gender mainstreaming and gender budgeting. Paper presented to a conference on 'Gender Equality and Europe's Future' European Commission, Brussels.

Eveline, J., Bacchi, C., \& Binns, J. (2009). Gender mainstreaming versus diversity mainstreaming: methodology and emancipatory politics. Gender, Work \& Organizations, 16(2), 198-216. https://doi.org/10.1111/j.1468-0432.2008.00427.

Farneti, G., Pozzoli, S., \& Nardo, M. T. (2005). La contabilità sociale negli enti locali, in Farneti G., \& Pozzoli S. (a cura di), Il bilancio sociale di mandato. Milano: Ipsoa.

Galizzi, G. (2012). Il bilancio di genere negli enti pubblici territoriali. Origini, strumenti e implicazioni aziendali. Milano: Franco Angeli.

Galizzi, G., \& Siboni, B. (2016). Positive action plans in Italian universities: does gender really matter? Meditari Accountancy Research, 24(2), 246-268. https://doi.org/10.1108/MEDAR- 09-2015-0062

Leardini, C., \& Rossi, G. (2011). Genere, territorio e programmazione: un'opportunità per l'azienda pubblica locale. Roma: Rirea.

Lehman, C. (2012). We've come a long way! Maybe! Re-imagining gender and accounting. Accounting, Auditing \& Accountability Journal, 25(2), 256-294. https://doi.org/10.1108/09513571211198764

Mahapatro, M. (2015). Mainstreaming gender: shift from advocacy to policy. Vision. The Journal of Business Perspective, 18(4), 309-315. https://doi.org/10.1177/0972262914551663

Martini, M. (2011). Il bilancio di genere nella prassi italiana. Indagine empirica sul comportamento degli enti locali. Rivista italiana di Ragioneria e di Economia Aziendale, Marzo-Aprile, 3-4, 191-203.

Moser, C. (2005). Has gender mainstreaming failed? International Feminist Journal of Politics, 7(4), 576-590, https://doi.org/10.1080/14616740500284573

Moser, C., \& Moser, A. (2005). Gender mainstreaming since Beijing: a review of success and limitations in international institutions. Gender \& $\quad$ Development, $13(2), 22$. 
https://doi.org/10.1080/13552070512331332283

Page, M.L. (2011). Gender mainstreaming - hidden leadership?. Gender, Work \& Organization, 18(3), 318-336, https://doi.org/10.1111/j.1468-0432.2010.00548

Pulejo, L. (2011). Gender approach in the planning of local and regional public authorities. Management Control, 2(25), 59-83. https://doi.org/10.3280/MACO2011-002004

Rao, G., \& Chakraborty, L. (2006). Fiscal decentralisation and local level gender responsive budgeting in Morocco: some observations. New Delhi: National Institute of Public Finance and Policy, 1-20.

Ricci, P., Siboni, B., \& Nardo, MT. (2014). La rendicontazione di sostenibilità. Evoluzione, linee guida ed esperienze in imprese, amministrazioni pubbliche e aziende non profit. Roma: Rirea. https://doi.org/10.17408/FC/590699

Sarraf, F. (2003). Gender-Responsive Government Budgeting. IMF Working Paper, New York.

Sharp, R. (1999). Women's budgets. In Lewis, M., Peterson, J. (Eds.), Elgar companion to feminist economics (pp. 764-770). New Jersey: Elgar.

Sharp, R. (2002). Moving forward: Multiple strategies and guiding goals. In Klot, J., Holvoet, N., \& Villagomez, E. (Eds.), Gender budget initiatives: strategies, concepts and experiences. New York: United Nations Development found for women (UNIFEM).

Stotsky, J. G. (2007). Budgeting with Women in Mind. Finance and Development, 44(2), 12-15.

\section{Notes}

Note 1. We refer in particular to the status of the region of Sardinia (art. 16), the Campania Region (art. 5, paragraph 3) and the Statute of Lazio (Art. 19).

\section{Copyrights}

Copyright for this article is retained by the author(s), with first publication rights granted to the journal.

This is an open-access article distributed under the terms and conditions of the Creative Commons Attribution license (http://creativecommons.org/licenses/by/4.0/). 